OPEN ACCESS

Edited by:

Samuel Wiebe

University of Calgary, Canada

Reviewed by:

Masaki Iwasaki,

National Center of Neurology and

Psychiatry, Japan

Bertil Rydenhag,

University of Gothenburg, Sweden

Taylor J. Abel,

University of Pittsburgh, United States

${ }^{*}$ Correspondence:

Vejay N. Vakharia

v.vakharia@ucl.ac.uk

${ }^{+}$Present address:

Aidan G. O'Keeffe,

School of Mathematical Sciences,

University of Nottingham, Nottingham, United Kingdom

Specialty section:

This article was submitted to

Epilepsy,

a section of the journal

Frontiers in Neurology

Received: 15 September 2021 Accepted: 01 November 2021

Published: 09 December 2021

Citation:

Marathe K, Alim-Marvasti A, Dahele K, Xiao F, Buck S, O'Keeffe AG,

Duncan JS and Vakharia VN (2021) Resective, Ablative and Radiosurgical Interventions for Drug Resistant Mesial Temporal Lobe Epilepsy: A Systematic Review and Meta-Analysis of Outcomes. Front. Neurol. 12:777845. doi: 10.3389/fneur.2021.777845

\section{Resective, Ablative and}

\section{Radiosurgical Interventions for Drug} Resistant Mesial Temporal Lobe Epilepsy: A Systematic Review and Meta-Analysis of Outcomes

\author{
Kajol Marathe ${ }^{1}$, Ali Alim-Marvasti ${ }^{1,2,3}$, Karan Dahele ${ }^{1}$, Fenglai Xiao ${ }^{1}$, Sarah Buck ${ }^{1}$, \\ Aidan G. O'Keeffe ${ }^{4 \dagger}$, John S. Duncan ${ }^{1,2}$ and Vejay N. Vakharia ${ }^{1,2 *}$
}

${ }^{1}$ Department of Clinical and Experimental Epilepsy, University College London, London, United Kingdom, ${ }^{2}$ National Hospital for Neurology and Neurosurgery, London, United Kingdom, ${ }^{3}$ Wellcome/EPSRC Centre for Interventional and Surgical Sciences, University College London, London, United Kingdom, ${ }^{4}$ Department of Statistical Science, University College London, London, United Kingdom

Objectives: One-third of individuals with focal epilepsy do not achieve seizure freedom despite best medical therapy. Mesial temporal lobe epilepsy (MTLE) is the most common form of drug resistant focal epilepsy. Surgery may lead to long-term seizure remission if the epileptogenic zone can be defined and safely removed or disconnected. We compare published outcomes following open surgical techniques, radiosurgery (SRS), laser interstitial thermal therapy (LITT) and radiofrequency ablation (RF-TC).

Methods: PRISMA systematic review was performed through structured searches of PubMed, Embase and Cochrane databases. Inclusion criteria encompassed studies of MTLE reporting seizure-free outcomes in $\geq 10$ patients with $\geq 12$ months followup. Due to variability in open surgical approaches, only comparative studies were included to minimize the risk of bias. Random effects meta-analysis was performed to calculate effects sizes and a pooled estimate of the probability of seizure freedom per person-year. A mixed effects linear regression model was performed to compare effect sizes between interventions.

Results: From 1,801 screened articles, 41 articles were included in the quantitative analysis. Open surgery included anterior temporal lobe resection as well as transcortical and trans-sylvian selective amygdalohippocampectomy. The pooled seizure-free rate per person-year was $0.72(95 \% \mathrm{Cl} 0.66-0.79)$ with trans-sylvian selective amygdalohippocampectomy, 0.59 (95\% Cl 0.53-0.65) with LITT, 0.70 $(95 \% \mathrm{Cl} 0.64-0.77)$ with anterior temporal lobe resection, $0.60(95 \% \mathrm{Cl} 0.49-$ $0.73)$ with transcortical selective amygdalohippocampectomy, $0.38(95 \% \mathrm{Cl} 0.14-$ 1.00) with RF-TC and 0.50 (95\% Cl 0.34-0.73) with SRS. Follow up duration and study sizes were limited with LITT and RF-TC. A mixed-effects linear regression model suggests significant differences between interventions, with LITT, ATLR and SAH demonstrating the largest effects estimates and RF-TC the lowest. 


\begin{abstract}
Conclusions: Overall, novel "minimally invasive" approaches are still comparatively less efficacious than open surgery. LITT shows promising seizure effectiveness, however follow-up durations are shorter for minimally invasive approaches so the durability of the outcomes cannot yet be assessed. Secondary outcome measures such as Neurological complications, neuropsychological outcome and interventional morbidity are poorly reported but are important considerations when deciding on first-line treatments.
\end{abstract}

Keywords: surgery, epilepsy, MTLE = mesial temporal lobe epilepsy, LITT = laser interstitial thermal therapy, radiosurgery, radiofrequency ablation (RFA)

\section{INTRODUCTION}

Despite optimal anti-seizure medication treatment, about onethird of individuals with epilepsy still suffer from seizures. If the seizure onset zone is accurately delineated during presurgical evaluation, surgery can result in sustained seizure freedom in patients with drug resistant focal epilepsy (1). The first randomized control trial of surgery for temporal lobe epilepsy showed seizure freedom rates of $58 \%$ in patients randomized to surgery compared to $8 \%$ randomized to best medical therapy at 12 months (2). Additional benefits of surgery include improved quality of life, cognitive performance, and minimizing risk of sudden unexpected death in epilepsy (SUDEP) (3). In this study, anteromesial temporal lobe resections (ATLR) were performed through a lateral neocortical resection of 4$4.5 \mathrm{~cm}$ in the dominant hemisphere and $6-6.5 \mathrm{~cm}$ in the nondominant hemisphere as measured from the temporal pole followed by amygdala and 1-3 cm hippocampal resection (2). Since then a number of different surgical approaches and modifications have been implemented including minimizing the lateral neocortical resection to $3 \mathrm{~cm}$, sparing of the superior temporal gyrus (4) and various selective approaches including transcortical (5), trans-sylvian (6) and subtemporal (7) amygdalohippocampectomy.

Each of these surgical modifications were undertaken with the aim of minimizing the neurological morbidity and neuropsychological sequelae secondary to collateral damage of nearby structures (8). Results of selective approaches have been variable with some studies showing improved neuropsychological outcomes and others showing worse seizure freedom rates than ATLR (9). Open surgical procedures all have inherent risks including visual field deficit, memory decline, stroke, hemorrhage and infection (10). More recently, novel "minimally invasive" techniques have been introduced with the aim of further reducing collateral injury and averting the need for craniotomy, including radiosurgery (SRS) (11), radiofrequency ablation (RF-TC) (12) and laser interstitial thermal therapy (LITT) (13). As with other novel procedures, early results have been mixed, principally due to small study sizes, short followup durations and as the technology matured. The lack of highquality comparative studies has made interpretation difficult (14). Coupled with this is the effect of the learning curve, whereby outcomes continue to improve as health-care systems gain experience in selecting patients for and performing these novel procedures. The introduction of novel technologies also has the potential to expose patients to additional harm until comparative long-term outcomes are known.

The objective of this study was to undertake a "Preferred Reporting Items for Systematic Reviews and Meta-Analysis" (PRISMA) systematic review and meta-analysis (15) of all ablative methods for the treatment of drug resistant mesial temporal lobe epilepsy.

\section{METHODS}

\section{Eligibility Criteria}

Eligibility for inclusion in the meta-analysis include peerreviewed publications in which full length English language manuscripts were available through electronic indexing comprising: a) clinical studies of patients with temporal lobe epilepsy, b) undergoing open epilepsy surgery as a treatment, or c) undergoing RF-TC, SRS or LITT as a treatment, d) with greater than 10 patients in the intervention arm and e) follow-up duration of $\geq 12$ months. Due to previous meta-analyses of open surgery outcomes $(16,17)$ only comparative open surgical studies were included to provide the highest levels of evidence. Studies that did not report Engel or ILAE outcomes or similar were also excluded.

\section{Information Sources}

Using the PRISMA guidelines (15) a structured search of the PubMed, Embase and Cochrane databases were undertaken. The last date of the search was September $9^{\text {th }} 2020$.

\section{Search Strategy}

Two independent researchers (VNV and FX) applied the search criteria defined following a PICOS (participants, interventions, comparators, outcomes and study design) approach to identify search terms. Participants included human studies reporting surgical treatments for drug resistant focal epilepsy. Surgical interventions included in the search terms were open surgical techniques including selective approaches and the numerous variations, as well as minimally invasive alternatives such as LITT, RF-TC, SRS and high frequency ultrasound. The main comparator for the quantitative analysis was seizurefree outcome.

The search terms can be found in the Supplementary Information.

The reference lists of all studies were searched and crossreferences for additional eligible studies considered. Previous 
systematic reviews and meta-analyses were also screened to capture additional studies $(9,16-18)$ not identified by the search terms.

\section{Outcomes}

During full text review data extraction was performed using a table with a predefined set of criteria including level of evidence, study design, comparison/control group and sample size. At a participant level data relating to side of surgery, patient age, duration of epilepsy, pre-operative MRI findings, post-operative histological findings, follow up duration, seizure outcome grading scale, post-operative seizure outcome, independent predictors of surgical outcome, neuropsychological tests performed, neuropsychological outcome, psychiatric outcome, operative morbidity and operative mortality was recorded. The main outcome for meta-analytic comparison was seizure-free outcome.

\section{Risk of Bias}

Anticipated sources of bias affecting seizure freedom included the seizure outcome grading scale and the duration of follow-up. To mitigate outcome reporting for different grading scales only comparable seizure outcomes were included in the quantitative analysis and where sufficient information was provided outcomes were converted from one grading scale to another; e.g., Engel class $1(\mathrm{~A}-\mathrm{D})=$ ILAE class $1,1 \mathrm{a}$ and 2 . The issue of overlapping patient cohorts in different papers also required careful analysis of the subjects so that duplicate cohorts were not included in the quantitative analysis. Where duplicate cohorts were unclear, authors were contacted for clarification.

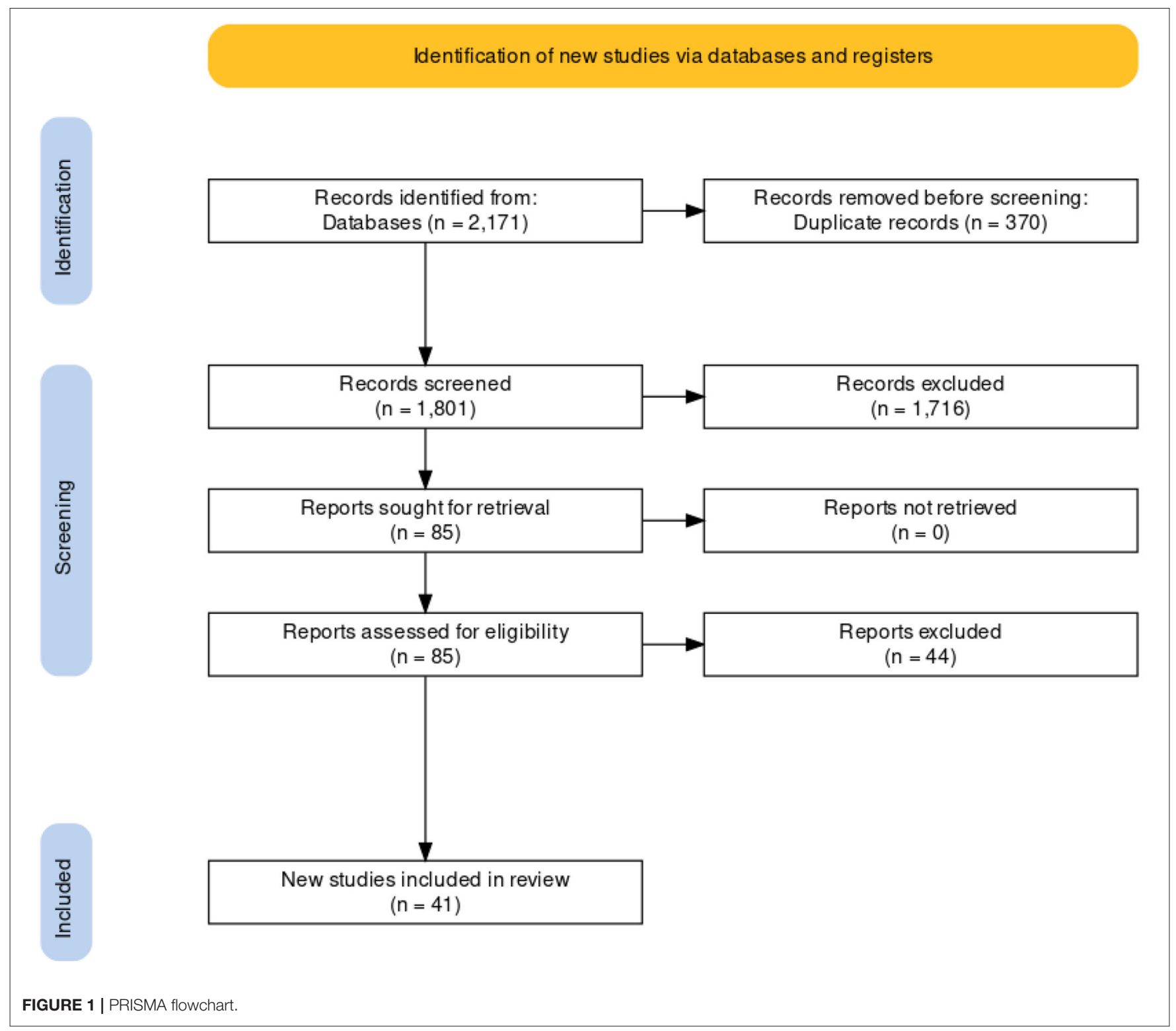




\section{Appraisal of Evidence}

Methodological Index for Non-Randomized Studies (MINORS) (19) and Jadad (20) scores for randomized control trials, respectively, were calculated independently by KM and KD. Low scores suggest less methodologically sound studies.

\section{Synthesis of Results}

For each surgery type, pooled estimates of the seizure-free rate per person-year were calculated, together with $95 \%$ confidence intervals, using a meta-analysis with inverse variance weighting.

The seizure-free rate per person-year estimates were calculated using the following equation to allow for the varying follow up durations between studies. As all patients are seizurefree immediately following intervention the time at risk of seizure-relapse can be taken as the total follow-up duration of the study with Person-years representing the sum of the total time at risk (total number of patients $\mathrm{x}$ follow up duration of study). This approach allows studies with differing follow-up times to be included in the meta-analysis and yields an informative method to compare studies having accounted for follow-up duration. In contrast, restricting the analysis to include only studies where follow-up is of the same length may result in selection bias and loss of information.

$$
\begin{aligned}
& \text { Seizure free rate per person year } \\
& =\frac{\text { Number of patient years seizure free }}{\text { Total number of patient years at risk }}
\end{aligned}
$$

A mixed-effects linear regression model was then performed with rate of seizure freedom per person-year and surgery method as a covariate to compare seizure-free rates between surgery types. A random effect for study was included in this model. Statistical analyses were performed using $\mathrm{R}$ (version 4.10).

\section{RESULTS}

In total, 2,171 studies were initially identified across three different databases. Following removal of duplicate and nonEnglish-language studies 1,801 manuscript titles and abstracts were screened. After applying the eligibility criteria, 85 underwent full text review. Any discrepancies between eligible publications were resolved by the senior author. From the full text review, 41 studies (19 on open surgery, 11 on LITT, four on radiofrequency and seven on radiosurgery) were included in the quantitative synthesis (Figure 1). No eligible studies were found on ultrasound. It was not possible to conduct a metaanalysis for neuropsychological outcomes or complications as no standardized tests or reporting criteria were adhered to.

\section{Open Surgery}

Where provided, patient demographics regarding side of resection, age at operation, and duration of epilepsy were comparable between open surgical interventions (Table 1). Overall, $86.5 \%$ of patients had MTS on pre-op MRIs and $79.5 \%$ had histologically proven MTS from 14 studies.

Nineteen studies comparing open surgical outcomes were included in the meta-analysis (Table 2). ATLR was compared to transcortical SAH in $63 \%(12 / 19)$, to trans-sylvian SAH in

\begin{tabular}{|c|c|c|c|}
\hline $\begin{array}{l}\text { Type of } \\
\text { intervention }\end{array}$ & $\begin{array}{l}\text { Side of } \\
\text { resection }\end{array}$ & $\begin{array}{l}\text { Age in years } \\
\text { (mean) }\end{array}$ & $\begin{array}{l}\text { Duration of } \\
\text { epilepsy in } \\
\text { years (mean) }\end{array}$ \\
\hline ATLR & $\begin{array}{l}206 \mathrm{R} \\
225 \mathrm{~L}\end{array}$ & $\begin{array}{l}33 \text { (from nine } \\
\text { studies) }\end{array}$ & $\begin{array}{l}25.5 \text { (from } 10 \\
\text { studies) }\end{array}$ \\
\hline $\begin{array}{l}\mathrm{SAH} \\
\text { (transcortical) }\end{array}$ & $\begin{array}{l}170 R \\
188 L\end{array}$ & $\begin{array}{l}35.1 \text { (from } 9 \\
\text { studies) }\end{array}$ & $\begin{array}{l}24.6 \text { (from nine } \\
\text { studies) }\end{array}$ \\
\hline $\begin{array}{l}\text { SAH } \\
\text { (transsylvian) }\end{array}$ & $\begin{array}{l}39 \mathrm{R} \text { (from two } \\
\text { studies) } \\
39 \mathrm{~L} \text { (from } \\
\text { two studies) }\end{array}$ & $\begin{array}{l}34.1 \text { (from } \\
\text { three studies) }\end{array}$ & $25.4^{*}$ \\
\hline
\end{tabular}

TABLE 1 | Open surgery patient characteristics.

* [only stated in Wendling et al. (21)].

$26 \%(5 / 19)$ and to an unspecified SAH technique in $11 \%(2 / 19)$. Of the studies comparing ATLR with transcortical SAH, 25\% (3/12) were prospective whilst the remaining $75 \%$ (9/12) were retrospective. One pilot RCT compared ATLR with transcortical $\mathrm{SAH}$ and transcortical parahippocampal gyrus resection (22). The study sample size was small and being a pilot study was underpowered to detect differences in Engel 1a outcome between any of the three techniques at one- and five-year follow-up. Despite this, visual field defects were noted to be significantly worse in the ATLR and SAH groups compared to the parahippocampectomy group.

One study, an RCT, reported the SAH group having a significantly lower seizure free outcome $(p=0.013)$ at 12 months (23). The remaining four studies did not report any significant differences between the two techniques including one paper (24) which was a subset of patients from Mackenzie et al. (25). Two studies did not specify the type of SAH performed so were excluded from the quantitative analysis for SAH $(25,26)$. One study evaluated a pediatric cohort (mean age 10.6 years) and found that ATL had a significantly better seizure outcome ( $p=$ 0.017 ) after a mean of 5.3 years (27). Studies comparing ATLR with radiosurgery (11) and with radiofrequency (28) were also included in the meta-analysis. In summary, of all the comparative open surgical techniques, two studies provided class one evidence $(22,23)$, one class two (29) and the remainder class three. A total of 2,183 patients were included in the quantitative synthesis with 1,248 undergoing ATLR and 935 undergoing SAH (transcortical 516, trans-sylvian 354 and unspecified 65).

Meta-analysis revealed a pooled effect size for overall seizure free rate per-person year of 0.70 (95\% CI $0.64-$ 0.77) for ATLR (Figure 2A), 0.60 (95\% CI 0.49-0.73) for transcortical selective amygdalohippocampectomy (Figure 2B) and 0.72 (95\% CI $0.66-0.79)$ for trans-sylvian selective amygdalohippocampectomy (Figure 2C).

Neuropsychological outcome was reported in 16 studies. Five comparative open surgery studies investigated changes in intellectual status after surgery. Across these studies, intelligence either remained stable $(27,30,31)$ or improved in both the visuospatial and verbal domain $(32,33)$. The improvement occurred as a combined effect of side and type of intervention, with mixed findings across studies. No post-surgical decline in intelligence was found. 
TABLE 2 | Open surgery.

\begin{tabular}{|c|c|c|c|c|c|c|c|c|}
\hline Authors & $\begin{array}{l}\text { Publication } \\
\text { Year }\end{array}$ & Type of study & Method & Comparator & $\begin{array}{l}\text { Number of } \\
\text { patients } \\
\text { followed up }\end{array}$ & $\begin{array}{l}\text { Duration of } \\
\text { follow up }\end{array}$ & $\begin{array}{l}\text { Seizure free } \\
\text { rate }\end{array}$ & $\begin{array}{c}\text { MINORS/ } \\
\text { JADAD score }\end{array}$ \\
\hline \multirow[t]{2}{*}{ Bate et al. } & 2007 & Retrospective & ATLR & Transcortical SAH & ATLR: 82 & 12 months & $\begin{array}{l}\text { ATLR: } 62 \% \\
(51 / 82)\end{array}$ & $16 / 24$ \\
\hline & & & & & SAH: 32 & & $\begin{array}{l}\text { SAH: 34\% } \\
(11 / 32)\end{array}$ & \\
\hline \multirow[t]{2}{*}{ Bujarski et al. } & 2013 & Retrospective & ATLR & Transcortical SAH & ATLR: 30 & 60 months & $\begin{array}{l}\text { ATLR: } 77 \% \\
(23 / 30)\end{array}$ & $15 / 24$ \\
\hline & & & & & SAH: 39 & & $\begin{array}{l}\text { SAH: } 69 \% \\
(27 / 39)\end{array}$ & \\
\hline \multirow[t]{2}{*}{ Mansouri et al. } & 2014 & Retrospective & ATLR & Transcortical SAH & ATLR: 75 & 24 months & $\begin{array}{l}\text { ATLR: } 51 \% \\
(38 / 75)\end{array}$ & $15 / 24$ \\
\hline & & & & & SAH: 21 & & $\begin{array}{l}\text { SAH: } 43 \% \\
(9 / 21)\end{array}$ & \\
\hline \multirow[t]{2}{*}{$\begin{array}{l}\text { Nascimento } \\
\text { et al. }\end{array}$} & 2016 & Retrospective & ATLR & Transcortical SAH & ATLR: 22 & 60 months & $\begin{array}{l}\text { ATLR: } 63.6 \% \\
(14 / 22)\end{array}$ & $18 / 24$ \\
\hline & & & & & SAH: 23 & & $\begin{array}{l}\text { SAH: } 73.9 \% \\
(17 / 23)\end{array}$ & \\
\hline \multirow[t]{2}{*}{ Paglioli et al. } & 2006 & Prospective & ATLR & Transcortical SAH & ATLR: 80 & $\begin{array}{l}\text { ATLR: } 80.4 \\
\text { months }\end{array}$ & $\begin{array}{l}\text { ATLR: } 91.3 \% \\
(73 / 80)\end{array}$ & $14 / 24$ \\
\hline & & & & & SAH: 81 & $\begin{array}{l}\text { SAH: } 54 \\
\text { months }\end{array}$ & $\begin{array}{l}\text { SAH: } 86.4 \% \\
(70 / 81)\end{array}$ & \\
\hline \multirow[t]{2}{*}{ Sagher et al. } & 2012 & Retrospective & ATLR & Transcortical SAH & ATLR: 51 & $\begin{array}{l}\text { ATLR: } 43.2 \\
\text { months }\end{array}$ & $\begin{array}{l}\text { ATLR: } 92.2 \% \\
(47 / 51)\end{array}$ & $15 / 24$ \\
\hline & & & & & SAH: 45 & $\begin{array}{l}\text { SAH: } 44.7 \\
\text { months }\end{array}$ & $\begin{array}{l}\text { SAH: } 95.6 \% \\
(43 / 45)\end{array}$ & \\
\hline \multirow[t]{2}{*}{ Tanriverdi et al. } & 2008 & Retrospective & ATLR & Transcortical SAH & ATLR: 50 & 60 months & $\begin{array}{l}\text { ATLR: } 64 \% \\
(32 / 50)\end{array}$ & $17 / 24$ \\
\hline & & & & & SAH: 50 & & $\begin{array}{l}\text { SAH: 64\% } \\
(32 / 50)\end{array}$ & \\
\hline \multirow[t]{2}{*}{ Tanriverdi et al. } & 2010 & Retrospective & ATLR & Transcortical SAH & ATLR: 123 & 12 months & $\begin{array}{l}\text { ATLR: } 65.9 \% \\
(81 / 123)\end{array}$ & $16 / 24$ \\
\hline & & & & & SAH: 133 & & $\begin{array}{l}\text { SAH: } 58.6 \% \\
(78 / 133)\end{array}$ & \\
\hline \multirow[t]{2}{*}{ Elliott et al. } & 2018 & Retrospective & ATLR & Transcortical SAH & ATLR: 61 & 63.6 months & $\begin{array}{l}\text { ATLR: } 77 \% \\
(47 / 61)\end{array}$ & $17 / 24$ \\
\hline & & & & & SAH: 18 & & $\begin{array}{l}\text { SAH: 44\% } \\
(8 / 18)\end{array}$ & \\
\hline \multirow[t]{2}{*}{ Mohan et al. } & 2018 & Retrospective & ATLR & Transcortical SAH & ATLR: 178 & 60 months & $\begin{array}{l}\text { ATLR: } 49 \% \\
(87 / 178)\end{array}$ & $16 / 24$ \\
\hline & & & & & SAH: 37 & & $\begin{array}{l}\text { SAH: 31\% } \\
(11 / 37)\end{array}$ & \\
\hline \multirow[t]{2}{*}{ Foged et al. } & 2018 & Prospective & ATLR & Transcortical SAH & ATLR: 34 & 12 months & $\begin{array}{l}\text { ATLR: } 73.5 \% \\
(25 / 34)\end{array}$ & $18 / 24$ \\
\hline & & & & & SAH: 22 & & $\begin{array}{l}\text { SAH: } 72.7 \% \\
(16 / 22)\end{array}$ & \\
\hline \multirow{2}{*}{$\begin{array}{l}\text { Arturo Alonso- } \\
\text { Vanegas } \\
\text { et al. }\end{array}$} & 2018 & $\begin{array}{l}\text { Prospective } \\
\text { RCT }\end{array}$ & ATLR & Transcortical SAH & ATLR: 14 & 60 months & $\begin{array}{l}\text { ATLR: } 64.3 \% \\
(9 / 14)\end{array}$ & $3 / 5$ \\
\hline & & & & & SAH: 15 & & $\begin{array}{l}\text { SAH: } 66.7 \% \\
(10 / 15)\end{array}$ & \\
\hline \multirow[t]{2}{*}{ Clusmann et al. } & 2002 & Retrospective & ATLR & Transsylvian SAH & ATLR: 98 & 38 months & $\begin{array}{l}\text { ATLR: } 69 \% \\
\text { (68/98) }\end{array}$ & $16 / 24$ \\
\hline & & & & & SAH: 138 & & $\begin{array}{l}\text { SAH: 70\% } \\
(96 / 138)\end{array}$ & \\
\hline \multirow[t]{2}{*}{ Lee et al. } & 1997 & Retrospective & ATLR & Transsylvian SAH & ATLR: 25 & 12 months & $\begin{array}{l}\text { ATLR: } 60 \% \\
(15 / 25)\end{array}$ & $17 / 24$ \\
\hline & & & & & SAH: 13 & & $\begin{array}{l}\text { SAH: } 38.5 \% \\
(5 / 13)\end{array}$ & \\
\hline
\end{tabular}




\begin{tabular}{|c|c|c|c|c|c|c|c|c|}
\hline Authors & $\begin{array}{l}\text { Publication } \\
\text { Year }\end{array}$ & Type of study & Method & Comparator & $\begin{array}{l}\text { Number of } \\
\text { patients } \\
\text { followed up }\end{array}$ & $\begin{array}{l}\text { Duration of } \\
\text { follow up }\end{array}$ & $\begin{array}{l}\text { Seizure free } \\
\text { rate }\end{array}$ & $\begin{array}{c}\text { MINORS/ } \\
\text { JADAD score }\end{array}$ \\
\hline \multirow[t]{2}{*}{ Morino et al. } & 2006 & Retrospective & ATLR & Transsylvian SAH & ATLR: 17 & 12 months & $\begin{array}{l}\text { ATLR: } 71 \% \\
(12 / 17)\end{array}$ & $16 / 24$ \\
\hline & & & & & SAH: 32 & & $\begin{array}{l}\text { SAH: } 78 \% \\
(25 / 32)\end{array}$ & \\
\hline \multirow[t]{2}{*}{ Schramm et al. } & 2011 & Prospective & ATLR & Transsylvian SAH & ATLR: 74 & 12 months & $\begin{array}{l}\text { ATLR: 83.8\% } \\
(62 / 74)\end{array}$ & $5 / 5$ \\
\hline & & & & & SAH: 125 & & $\begin{array}{l}\mathrm{SAH}: 67.2 \% \\
(84 / 125)\end{array}$ & \\
\hline \multirow[t]{2}{*}{ Wendling et al. } & 2013 & Retrospective & ATLR & Transsylvian SAH & ATLR: 49 & 84 months & $\begin{array}{l}\text { ATLR: } 85.7 \% \\
(42 / 49)\end{array}$ & $18 / 24$ \\
\hline & & & & & SAH: 46 & & $\begin{array}{l}\text { SAH: } 78.3 \% \\
(36 / 46)\end{array}$ & \\
\hline \multirow[t]{2}{*}{ Arruda et al. } & 1996 & Retrospective & ATLR & Unspecified SAH & ATLR: 37 & 12 months & $\begin{array}{l}\text { ATLR: } 68 \% \\
(25 / 37)\end{array}$ & $17 / 24$ \\
\hline & & & & & SAH: 37 & & $\begin{array}{l}\text { SAH: } 76 \% \\
(28 / 37)\end{array}$ & \\
\hline \multirow[t]{2}{*}{ Mackenzie et al. } & 1997 & Retrospective & ATLR & Unspecified SAH & ATLR: 72 & 12 months & $\begin{array}{l}\text { ATLR: } 60 \% \\
(43 / 72)\end{array}$ & $15 / 24$ \\
\hline & & & & & SAH: 28 & & $\begin{array}{l}\text { SAH: } 21 \% \\
(6 / 28)\end{array}$ & \\
\hline
\end{tabular}

Four studies investigated language functions. Language was reported to either remain stable $(30,31)$ or decline $(34,35)$ after surgery, but no study reported post-surgical improvement. Decline in language abilities were observed irrespective of side or procedure (35) with greatest declines reported following leftsided resections and ATLR (34).

Nine studies which looked at open surgery only investigated visuospatial memory and 13 investigated verbal memory. Four studies reported no post-operative changes in visuospatial memory whereas for verbal memory, just over half of studies suggested a decline $(21,24,29,30,33,35,36)$. Post-operative improvements in memory are reported for functions subserved by the non-operated side, with improvements in visuospatial memory occurring after left-sided resections $(33,34)$ and verbal memory gains after right-sided resections (32). Interventionspecific improvement of memory is also observed, with greater improvement after SAH than after ATLR, particularly for visuospatial memory $(21,33,34)$. Visuospatial memory also declined after right-sided resection, irrespective of the intervention type (34) or with greater decline after ATLR compared to SAH (33). The factors influencing verbal memory decline varied across studies, with either a decline irrespective of side or type of resection (35), after left-sided resection irrespective of the intervention type $(21,29)$, or conflicting findings regarding the effect of intervention [i.e. with more decline after SAH $(30,33)$ or $\operatorname{ATLR}(24,29,36)]$.

\section{Complications}

Data regarding post-operative complications were missing in $8 / 19$ of the comparative open surgical studies, with one study only reporting cognitive and psychiatric complications (31). Even in those that did report complications, reporting was often not comprehensive. Complications reported here are described for the open surgical techniques as reliable differentiation between SAH and ATLR was not possible. The two studies that compared ATLR with radiofrequency and radiosurgery are also included here for the ATLR arm only. Of the studies that reported complications, the most common complication was visual field defects, occurring in $4 \%(63 / 1,548)$ of patients. This is much lower than complications reported for open surgery where formal perimetry was utilized (37) and because of nonrecognition of such defects in many studies. Most studies did not use perimetry and only reported clinically significant visual defects. Cranial nerve palsy rate was $0.78 \%(12 / 1548)$ and $1.29 \%(20 / 1548)$ suffered from infection-related complications including meningitis, mastoiditis and one case of osteomyelitis. From all identified studies mortality was $0.82 \%(18 / 2,183)$ over a period of 5 (38) to 7 (29) years post-surgery.

Psychiatric complications such as anxiety, depression and psychosis were reported in $1.1 \%(17 / 1,548)$ patients, however this was only across the four studies that reported such outcomes. Therefore, this will be a gross underestimate as many studies did not report psychiatric outcomes. Neurological complications were reported in $1.87 \%(29 / 1,548)$ patients and included dysphasia, dysnomia, hemiparesis, hemiplegia, hypoacusis and cerebritis. Other complications included CSF leaks or collections $(10 / 1,548)$, pseudomeningoceles $(4 / 1,548)$, haematoma $(9 / 1,548)$, jaw pain $(4 / 1,548)$, pulmonary embolism $(2 / 1,548)$, venous thrombosis $(5 / 1,548)$ and ventilator associated pneumonia $(1 / 1,548)$. Two papers did not provide a full breakdown (23, 34 ), but reported neurological complications in 3-5.2\%, overall surgical complication rate as $8.5 \%$ (34) and permanent morbidity 


\section{A ATLR}

Study

Arruda et al. 1996

Arturo Alonso-Vanegas et al. 2018

Barbaro et al. 2018

Bate et al. 2007

Bujarski et al. 2013

Clusmann et al. 2002

Elliott et al. 2018

Foged et al. 2018

Lee et al. 1997

Mackenzie et al. 1997

Mansouri et al. 2014

Mohan et al. 2018

Moles et al. 2018

Morino et al. 2006

Nascimento et al. 2016

Paglioli et al. 2006

Sagher et al. 2012

Schramm et al. 2011

Tanriverdi et al. 2008

Tanriverdi et al. 2010

Wendling et al. 2013

Pooled seizure-free rate per person-year

Heterogeneity: $I^{2}=85 \%, \tau^{2}=0.0278, p<0.01$
Seizure-free rate per person-year

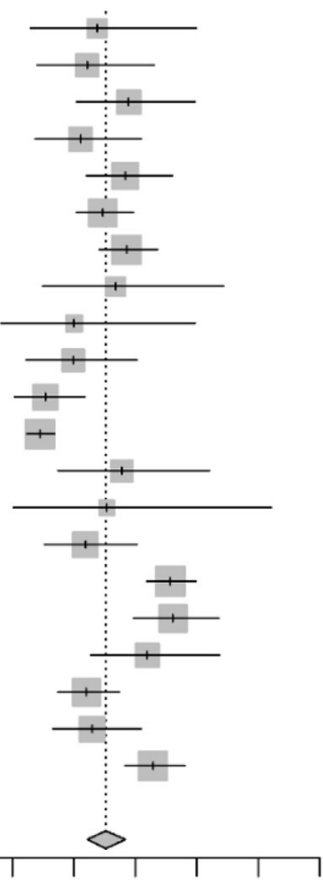

$\begin{array}{llllllll}0 & 0.2 & 0.4 & 0.6 & 0.8 & 1 & 1.2 & 1.4\end{array}$
Rate $\quad 95 \%-\mathrm{Cl}$ Weight

$0.68[0.46 ; 1.00] \quad 3.0 \%$

$0.64[0.48 ; 0.86] \quad 4.0 \%$

$0.78[0.61 ; 1.00] \quad 4.6 \%$

$0.62[0.47 ; 0.82] \quad 4.3 \%$

$0.77[0.64 ; 0.92] \quad 5.5 \%$

$0.69[0.61 ; 0.79] \quad 6.2 \%$

$0.77[0.68 ; 0.87] \quad 6.4 \%$

$0.74[0.50 ; 1.09] \quad 3.0 \%$

$0.60[0.36 ; 1.00] \quad 2.1 \%$

$0.60[0.44 ; 0.81] \quad 4.0 \%$

$0.51[0.40 ; 0.63] \quad 4.9 \%$

$0.49[0.44 ; 0.54] \quad 6.7 \%$

$0.76[0.55 ; 1.04] \quad 3.7 \%$

$0.71[0.40 ; 1.24] \quad 1.8 \%$

$0.64[0.50 ; 0.80] \quad 4.8 \%$

$0.91[0.84 ; 1.00] \quad 6.8 \%$

$0.92[0.79 ; 1.07] \quad 6.0 \%$

$0.84[0.65 ; 1.07] \quad 4.6 \%$

$0.64[0.55 ; 0.75] \quad 5.9 \%$

$0.66[0.53 ; 0.82] \quad 5.0 \%$

$0.86[0.76 ; 0.96] \quad 6.5 \%$

$0.70[0.64 ; 0.77] 100.0 \%$

\section{B SAH trans-cortical}

Study

Arturo Alonso-Vanegas et al. 2018

Bate et al. 2007

Bujarski et al. 2013

Elliott et al. 2018

Foged et al. 2018

Mansouri et al. 2014

Mohan et al. 2018

Nascimento et al. 2016

Paglioli et al. 2006

Sagher et al. 2012

Tanriverdi et al. 2008

Tanriverdi et al. 2010

Pooled seizure-free rate per person-year

Heterogeneity: $I^{2}=88 \%, \tau^{2}=0.1053, p<0.01$
Seizure-free rate per person-year

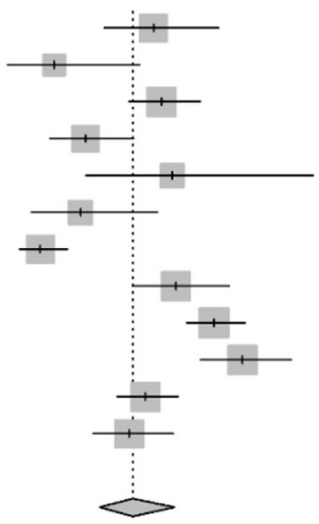

$\begin{array}{llllllll}0 & 0.2 & 0.4 & 0.6 & 0.8 & 1 & 1.2 & 1.4\end{array}$
Rate $\quad 95 \%-\mathrm{Cl}$ Weight

$0.67[0.51 ; 0.88] \quad 8.5 \%$

$0.34[0.19 ; 0.62] \quad 5.4 \%$

$0.69[0.58 ; 0.82] \quad 9.4 \%$

$0.44[0.33 ; 0.60] \quad 8.2 \%$

$0.73[0.45 ; 1.19] \quad 6.3 \%$

$0.43[0.27 ; 0.68] \quad 6.6 \%$

$0.30[0.23 ; 0.39] \quad 8.6 \%$

$0.74[0.60 ; 0.91] \quad 9.1 \%$

$0.86[0.77 ; 0.97] \quad 9.8 \%$

$0.96[0.82 ; 1.12] \quad 9.5 \%$

$0.64[0.55 ; 0.75] \quad 9.5 \%$

$0.59[0.47 ; 0.73] \quad 9.0 \%$

$0.60[0.49 ; 0.73] 100.0 \%$

FIGURE 2 | Continued 


\section{c SAH trans-sylvian}

Study

Clusmann et al. 2002

Lee et al. 1997

Morino et al. 2006

Schramm et al. 2011

Wendling et al. 2013

Pooled seizure-free rate per person-year

Heterogeneity: $I^{2}=13 \%, \tau^{2}=0.0014, p=0.33$
Rate $\quad 95 \%-\mathrm{Cl}$ Weight

$0.70[0.62 ; 0.78] \quad 42.4 \%$

$0.38[0.16 ; 0.92] \quad 1.0 \%$

$0.78[0.53 ; 1.16] \quad 4.8 \%$

$0.67[0.54 ; 0.83] \quad 14.9 \%$

$0.78[0.69 ; 0.89] \quad 37.0 \%$

$0.72[0.66 ; 0.79] 100.0 \%$

\section{Radiofrequency thermocoagulation}

Study

Fan et al. 2019

Moles et al. 2018

Parrent et al. 1999

Vojtech et al. 2014

Pooled seizure-free rate per person-year

Heterogeneity: $I^{2}=83 \%, \tau^{2}=0.7374, p<0.01$
Rate $\quad 95 \%-\mathrm{Cl}$ Weight

$0.76[0.47 ; 1.24] \quad 30.2 \%$

$0.02[0.00 ; 0.38] \quad 8.8 \%$

$0.21[0.11 ; 0.41] \quad 28.3 \%$

$0.70[0.62 ; 0.80] \quad 32.6 \%$

$0.38[0.14 ; 1.00] 100.0 \%$

E

Stereotactic radiosurgery

Study

Barbaro et al. 2009

Barbaro et al. 2018

Bartolomei et al. 2008

Regis et al. 2000

Regis et al. 2004

Rheims et al. 2008

Vojtech et al. 2009

Pooled seizure-free rate per person-year Heterogeneity: $t^{2}=78 \%, \tau^{2}=0.2214, p<0.01$
Seizure-free rate per person-year

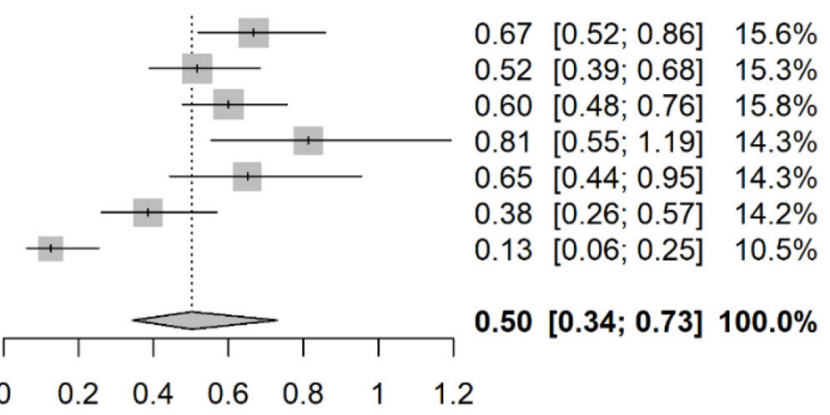

FIGURE 2 | Continued 


\section{F LITT}

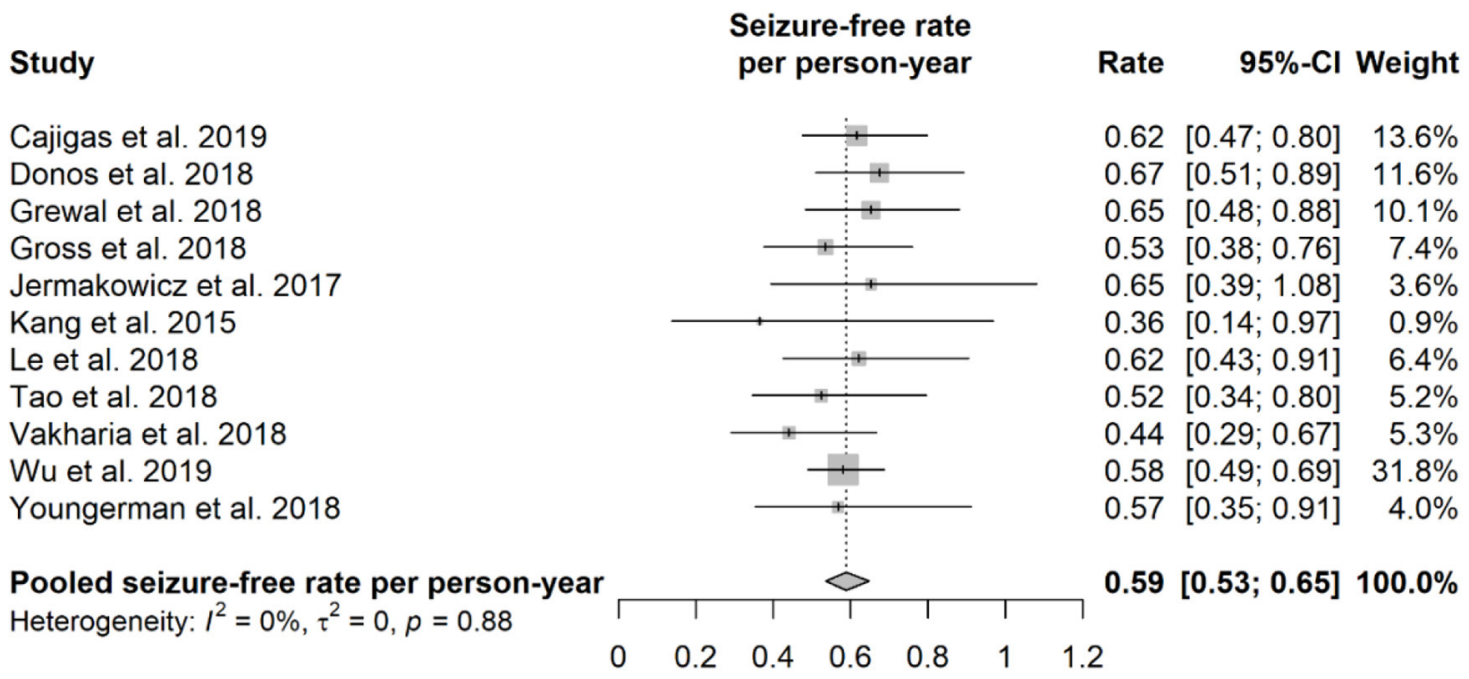

\section{G Comparison of treatment effect estimates} The table below shows the fitted estimates from a mixed effects linear regression model with rate of seizure freedom per person-year and
surgery method as a covariate with a fixed effect. A random effect for study was included in this model.

\begin{tabular}{lcc}
\hline $\begin{array}{l}\text { Surgery Method } \\
\text { ATL }\end{array}$ & $\begin{array}{c}\text { Seizure-free rate per person } \\
\text { year estimate }\end{array}$ & $\begin{array}{l}\text { 95\% Confidence Interval } \\
\text { GammaKnife }\end{array}$ \\
LiTT & 0.72 & $(0.65,0.80)$ \\
Radiofrequency & 0.53 & $(0.46,0.67)$ \\
SAH-Transcortical & 0.36 & $(0.17,0.53)$ \\
SAH-Transsylvian & 0.64 & $(0.55,0.73)$ \\
Random Effect Variance estimate $=0.02$ & 0.65 & $(0.53,0.78)$ \\
We performed an analysis of deviance to compare the above model to a model that does not contain surgery method as a covariate. \\
This yielded a test statistic of 18.38 which, when compared to the quantiles of a Chi-squared distribution with five degrees of freedom, \\
produced a P-value of 0.003. This implies that there is strong evidence to suggest a difference in the seizure-free rate when comparing \\
different surgery methods. RF-TC returned the lowest treatment effect estimate whilst ATL returned the greatest.
\end{tabular}

FIGURE 2 | Forest plots of effect sizes and 95\% confidence intervals. (A) ATLR. (B) SAH trans-cortical. (C) SAH trans-sylvian. (D) Radiofrequency thermocoagulation. (E) Stereotactic radiosurgery. (F) LITT. (G) Comparison of treatment effect estimates.

as $1.67 \%$. Overall, the heterogeneity in reported complications was difficult to synthesize, but overall mortality and morbidity was relatively low.

\section{Risk of Bias}

The median MINORS score for comparative studies was $16 / 24$, indicating that most studies contained methodological flaws and may therefore contribute a moderate degree of bias. One RCT returned a JADAD score of $3 / 5$ (22), indicating a moderate degree of bias, whilst another RCT scored $5 / 5(23)$.

\section{Radiofrequency Thermocoagulation}

Four studies were included in the quantitative analysis (12, 28, 39, 40 ). Where reported, the mean age was 33.6 years and the mean duration of epilepsy was 20.3 years, with some studies reporting median ages only. 64 patients underwent left-sided procedures, and 37 patients underwent right-sided procedures. Laterality was not reported in one study (28). There was unclear reporting of the exact number of patients with MTS on MRI, however it was present in the majority. Histopathological confirmation of MTS was not available as this is a lesioning technique.

One study (39) was prospective, one study did not specify (12), and the remainder were retrospective. The range of reported 
TABLE 3 | Radiofrequency.

\begin{tabular}{|c|c|c|c|c|c|c|c|c|}
\hline Authors & $\begin{array}{c}\text { Publication } \\
\text { Year }\end{array}$ & Type of study & Method & Comparator & $\begin{array}{l}\text { Number of } \\
\text { patients } \\
\text { followed up }\end{array}$ & $\begin{array}{l}\text { Duration of } \\
\text { follow up }\end{array}$ & Seizure free rate & MINORS/JADAD score \\
\hline Parrent et al. & 1999 & Unclear & Radiofrequency & $\mathrm{N} / \mathrm{A}$ & 19 & 25.8 months & $22 \%(4 / 19)$ & $9 / 16$ \\
\hline Vojtech et al. & 2014 & Retrospective & Radiofrequency & $\mathrm{N} / \mathrm{A}$ & 61 & 63.6 months & $70.5 \%(43 / 61)$ & $10 / 16$ \\
\hline Fan et al. & 2019 & Prospective & Radiofrequency & N/A & 21 & 12 months & $76.2 \%(16 / 21)$ & $11 / 16$ \\
\hline \multirow[t]{2}{*}{ Moles et al. } & 2018 & Retrospective & Radiofrequency & ATLR & $\begin{array}{l}\text { Radiofrequency: } \\
21\end{array}$ & 12 months & Radiofrequency: $0 \%(0 / 21)$ & $16 / 24$ \\
\hline & & & & & ATLR:49 & & ATLR: $75.5 \%(37 / 49)$ & \\
\hline
\end{tabular}

seizure freedom was between 0 and $76.2 \%$ seizure free at 12 months (Table 3). An single study which followed an overlapping patient cohort with Vojtech et al. (40), compared RF-TC to ATLR and reported no difference in Engel 1 outcomes of 79.3\% (23/29) and $76.5 \%(13 / 17)$ at 5 year follow up, respectively (41). In contrast, a later study comparing RF-TC to ATLR (28), reported none $(0 / 21)$ of the patients in the RF-TC group were seizure free whereas $75.5 \%$ (37/49) of the patients in the ATLR group had an Engel 1a outcome at 12-month follow up $(p<0.0001)$. Overall, 122 patients from studies equating to level two, three and four evidence were included in the quantitative synthesis. A randomeffects meta-analysis yielded a pooled seizure free rate estimate per person-year of 0.38 (95\% CI 0.14-1.00) (Figure 2D).

Neuropsychological outcome was reported in one of four studies. This single study suggested better post-operative neuropsychological outcome in the RF-TC group (41) compared with the ATLR group.

Complications were heterogenous across the studies. $4.1 \%(5 / 122)$ patients had haematomas, which were mostly asymptomatic $(12,40)$. Other complications included transitory anosmia (1/122), upper quadrantanopia (1/122), meningitis $(2 / 122)$, pulmonary embolism in a patient with hereditary coagulopathy (1/122), and an asymptomatic retention of an electrode fragment $(2 / 122)$. No complications or mild headache were reported in $36.1 \%$ (44/122) patients (40). The most serious early complications were a small intracerebral haematoma and hydrocephalus which resolved with ventricular drainage (40). Reported mortality was $5 \%$ (3/61) in the report by Vojtech et al. (40), due to one suicide, an unrelated accident and extracranial malignancy. Mortality was $0 \%$ in all other studies. No mortality was directly related to the operative procedure. Psychiatric complications were reported in 6/61 patients (40).

\section{Risk of Bias}

The median MINORS score for radiofrequency was 10/16 for non-comparative studies and 16/24 for a single comparative study indicating a moderate risk of bias due to methodological flaws.

\section{Stereotactic Radiosurgery}

Seven studies (three prospective) comprising 133 patients were included in the meta-analysis (Table 4). Two patients in the paper by Rheims et al. (42) and six patients in the paper by Vojtech et al. (43) overlapped with those of the Marseilles cohort (44) and were excluded from the analysis. The mean duration of epilepsy was similar between studies, with an overall mean of 24.1 years. Between 93 and 100\% had MTS on MRI scan. Where laterality was reported, 48 procedures were left-sided and 40 were on the right.

Due to the delay in treatment benefit following SRS, seizure free outcomes were reported from 24 months. All studies reported on the use of the gamma knife (Elekta AB, Sweden). One study compared high (24Gy) and low (20Gy) dose SRS, reporting improved seizure free outcomes but alongside increased minor complications associated with use of the higher dose (45). The highest level of evidence was from the ROSE randomized control trial comparing SRS to ATLR (11). The trial was terminated early due to poor recruitment, but even at this stage revealed that seizure free outcome rates following ATLR were superior to SRS ( $p=0.82$ at $15 \%$ non-inferiority margin). Most studies provided level three and four evidence with two papers providing level two evidence $(44,45)$ and a single RCT providing level one evidence (11). The pooled seizure-free rate per personyear was 0.50 (95\% CI 0.34-0.73) after a treatment delay of 24 months (Figure 2E). Neuropsychological outcome was reported in 5/7 studies. One study directly compared outcome between SRS and open surgery (ATLR) and showed less risk of verbal memory deterioration after SRS, and less risk of visuospatial memory deterioration after ATLR (11). Another neuropsychological study reported decline in verbal memory with high dose (24 Gy) but not low dose (20 Gy) Gamma Knife to the dominant amygdalohippocampal complex (46). Other studies either reported some improvement in a subset of the patients or little post-operative cognitive change.

\section{Complications}

Mortality was $1.5 \%$ (2/133) owing to one case of SUDEP (47) and one case of right cerebellar hemorrhage unrelated to the surgery (42). The classification of what defined "serious" adverse effects were not standardized throughout studies. Additionally, definitions of "early" and "late" complications were not specified. Cerebral oedema was reported in $7.5 \%(10 / 133)$ of patients undergoing SRS. One case of serious cerebral oedema not responding to dexamethasone required temporal lobectomy (45). Interestingly, Bartolomei (47) did not report cerebral oedema in any of their patients. Corticosteroid treatment was needed in $47.4 \%$ (63/133) when excluding overlapping patients. Other side effects included headaches (24/133), pin-site infection (1/133), 
TABLE 4 | Stereotactic radiosurgery.

\begin{tabular}{|c|c|c|c|c|c|c|c|c|}
\hline Authors & $\begin{array}{l}\text { Publication } \\
\text { Year }\end{array}$ & Type of study & Method & Comparator & $\begin{array}{l}\text { Number of } \\
\text { patients } \\
\text { followed up }\end{array}$ & $\begin{array}{l}\text { Duration of } \\
\text { follow up }\end{array}$ & $\begin{array}{l}\text { Seizure free } \\
\text { rate }\end{array}$ & $\begin{array}{c}\text { MINORS/ } \\
\text { JADAD score }\end{array}$ \\
\hline Barbaro et al. & 2009 & $\begin{array}{l}\text { Prospective } \\
\text { RCT (low dose } \\
\text { vs high dose) }\end{array}$ & $\begin{array}{l}\text { Gamma } \\
\text { Knife }\end{array}$ & $\begin{array}{l}\text { Low dose vs high } \\
\text { dose }\end{array}$ & 30 & 36 months & $67 \%(20 / 30)$ & $3 / 5$ \\
\hline \multirow[t]{2}{*}{ Barbaro et al. } & 2018 & $\begin{array}{l}\text { Prospective } \\
\text { RCT (ROSE } \\
\text { trial) }\end{array}$ & $\begin{array}{l}\text { Gamma } \\
\text { Knife }\end{array}$ & ATLR & $\begin{array}{l}\text { Gamma } \\
\text { Knife: } 31\end{array}$ & 36 months & $\begin{array}{l}\text { Gamma } \\
\text { Knife: } 52 \% \\
(16 / 31)\end{array}$ & $3 / 5$ \\
\hline & & & & & ATLR: 27 & & $\begin{array}{l}\text { ATLR: } 78 \% \\
(21 / 27)\end{array}$ & \\
\hline $\begin{array}{l}\text { Bartolomei } \\
\text { et al. }\end{array}$ & 2008 & Retrospective & $\begin{array}{l}\text { Gamma } \\
\text { Knife }\end{array}$ & $\mathrm{N} / \mathrm{A}$ & 15 & 96 months & $60 \%(9 / 15)$ & $9 / 16$ \\
\hline Regis et al. & 2000 & Retrospective & $\begin{array}{l}\text { Gamma } \\
\text { Knife }\end{array}$ & N/A & 16 & 24 months & $81 \%(13 / 16)$ & $8 / 16$ \\
\hline Regis et al. & 2004 & Prospective & $\begin{array}{l}\text { Gamma } \\
\text { Knife }\end{array}$ & N/A & 20 & 24 months & $65 \%(13 / 20)$ & $11 / 16$ \\
\hline Rheims et al. & 2008 & Retrospective & $\begin{array}{l}\text { Gamma } \\
\text { Knife }\end{array}$ & N/A & 13 & 60 months & $38.5 \%(5 / 13)$ & $10 / 16$ \\
\hline Vojtech et al. & 2009 & Retrospective & $\begin{array}{l}\text { Gamma } \\
\text { Knife }\end{array}$ & $\mathrm{N} / \mathrm{A}$ & 8 & 91.5 months & $12.5 \%(1 / 8)$ & $9 / 16$ \\
\hline
\end{tabular}

dizziness (2/133), nausea (2/133), vomiting (2/133), serious seizure exacerbation (2/133), status epilepticus (2/133) and visual field defects in the realm of $35.3 \%$ (47/133) when excluding overlapping patients' results. In one study, $93 \%$ of those formally tested had some form of visual field defect (37), even though only 10 were reported to have a superior quadrantanopia. Vojtech et al. (48) reports an even-longer term mean follow up time of 16 years of the complications from Vojtech et al., stressing the need for life-long MRI follow up in patients undergoing gamma knife radiosurgery, as delayed radio-necrosis and cyst formation were reported. Two patients developed psychosis (43) and one reported developing depression post-surgery (44).

\section{Risk of Bias}

For the two RCTs, JADAD scores were 3/5. A median MINORS score of $9 / 16$ was scored for the remaining studies, all of which were non-comparative, indicating a moderate degree of bias within these studies.

\section{Laser Interstitial Thermal Therapy}

Two studies $(49,50)$ reported duplicate patient cohorts and were excluded from the analysis. From the 11 studies reporting LITT outcomes, two were prospective $(51,52)$ and nine were retrospective (see Table 5). Overall, 520 patients were followed up, ranging between a mean of 12 months $(13,53-56)$ and 43 months (57). Engel 1 outcomes for the studies ranged between $44 \%$ (14) and $67.4 \%$ (58). The mean age of patients was 41.9 years, mean duration of epilepsy was reported in nine studies as 23.8 years, an average of $74.2 \%$ patients undergoing LITT had MTS on MRI, and the side of resection was reported by nine studies as 263 (left) and 201 (right).

A retrospective case series revealed that trajectories with a medial course through the hippocampal head resulted in less mesial hippocampal head remnant and was associated with improved seizure free outcome (53). Seizure freedom rates were found to be twice as high in patients with MTS compared to non-MTS (13), although a separate study reported similar seizure freedom rates between MTS and non-MTS when stereoelectroencephalography (SEEG) was utilized to prove mesial temporal lobe onset (55). Overall, using data from the 11 LITT studies included in the quantitative analysis a pooled estimate of the seizure-free rate per person-year was $0.59(95 \%$ CI 0.53-0.65) (Figure 2F).

\section{Neuropsychological Outcome}

Neuropsychological outcomes were reported in six of the eleven studies. Amongst these, three investigated visuospatial memory and six investigated verbal memory. Only one directly compared post-operative neuropsychological outcomes between LITT and ATLR (50). This demonstrated that the ATLR group showed post-surgery decline in visuospatial memory, whereas those who underwent LITT remained stable. Other studies report a significant decline in verbal memory after LITT in the dominant hemisphere $(53,58)$ whilst others report significant decreases in verbal intelligence but an improvement in visuospatial intelligence in the dominant hemisphere (58). In contrast, Gross et al. (13) reported an improvement in delayed verbal recall for non-dominant procedures. With regards to language function, it remained overall stable, with a smaller decline in memory in nondominant procedures (59) or improved, for both dominant and non-dominant procedures (50). 
TABLE 5 | Laser interstitial thermal therapy.

\begin{tabular}{|c|c|c|c|c|c|c|c|}
\hline Authors & $\begin{array}{l}\text { Publication } \\
\text { Year }\end{array}$ & $\begin{array}{l}\text { Type of } \\
\text { study }\end{array}$ & Method & $\begin{array}{l}\text { Number of } \\
\text { patients } \\
\text { followed up }\end{array}$ & $\begin{array}{l}\text { Duration of } \\
\text { follow up }\end{array}$ & $\begin{array}{l}\text { Seizure free } \\
\text { rate }\end{array}$ & $\begin{array}{c}\text { MINORS/JADAD } \\
\text { score }\end{array}$ \\
\hline $\begin{array}{l}\text { Jermakowicz } \\
\text { et al. }\end{array}$ & 2017 & Retrospective & LITT & 23 & 12 months & $65 \%(15 / 23)$ & $10 / 16$ \\
\hline Vakharia et al. & 2018 & Retrospective & LITT & 25 & 24.4 months & $44 \%(11 / 25)$ & $11 / 16$ \\
\hline $\begin{array}{l}\text { Youngerman } \\
\text { et al. }\end{array}$ & 2018 & Retrospective & LITT & 30 & 12 months & $57 \%(17 / 30)$ & $12 / 16$ \\
\hline Le et al. & 2018 & Prospective & LITT & 29 & 18 months & $62 \%(18 / 29)$ & $11 / 16$ \\
\hline Cajigas et al. & 2019 & Retrospective & LITT & 26 & 42.9 months & $\begin{array}{l}61.5 \% \\
(16 / 26)\end{array}$ & $11 / 16$ \\
\hline Tao et al. & 2018 & Prospective & LITT & 21 & 24 months & $52 \%(11 / 21)$ & $13 / 16$ \\
\hline Grewal et al. & 2018 & Retrospective & LITT & 23 & 34 months & $\begin{array}{l}65.2 \% \\
(15 / 23)\end{array}$ & $10 / 16$ \\
\hline
\end{tabular}

\section{Complications}

The reporting of complications varied across studies, with some distinguishing between asymptomatic and symptomatic visual field defects. Visual field dysfunction, including those that were transient and asymptomatic were reported in $7.5 \%$ (39/520) of patients; however, only a subset of patients had formal visual field testing. Cranial nerve palsies of the third and fourth cranial nerves were reported in $1.5 \%$ $(8 / 520)$ patients, the majority of which were transient. Post-operative hemorrhage occurred in $0.96 \%(5 / 520)$ patients and aseptic meningitis occurred in 1/520. Other complications occurred in $7.31 \%$ (38/520). Mortality following LITT was $0.57 \%$ (three patients died: two from suicide, one from SUDEP).

\section{Psychiatric Outcome}

The psychiatric complication rate was $4.4 \%$ (23/520), but this was only reported across five studies. Worsening of existing mood disorders was reported in 10 patients, worsening of mood in general was reported in two individuals and transient anxiety was reported in three. Two others needed hospitalization due to psychosis (14) or acute postoperative psychiatric complications (51), and five were diagnosed with a new onset affective disorder.

\section{Risk of Bias}

The median MINORs score for LITT studies was 10/16, indicating a moderate degree of bias in the studies.

\section{DISCUSSION}

\section{Primary Outcome}

The primary aim of this meta-analysis was to review the effectiveness of different interventional techniques for MTLE, by comparing seizure freedom rates for resective, ablative and SRS treatments. We were also interested in stereotactic radiosurgery as no meta-analysis to date has attempted to compare this to LITT, radiofrequency and open surgical methods. We also compared seizure free outcomes between ATLR, trans-sylvian and transcortical SAH. Due to heterogeneity within interventions, comparison within the random-effects model was not possible. However, a mixed-effects linear regression model suggested significant differences between interventions, with LITT, ATLR and SAH demonstrating the largest effects estimate and RF-TC the lowest (Figure 2G).

\section{Open Surgery}

Between the open surgical methods, our mixed effects model for seizure-free rate per person year estimates were greatest 
for ATLR, followed by transsylvian SAH and then transcortical SAH, but overlap of the 95\% confidence intervals prevents determination of comparative superiority. With regard to neuropsychological outcomes, open surgery does not impede on intellectual status and often even leads to post-operative improvement. Language ability, however, is prone to post-surgical decline, but the factors influencing such decline (such as the side and type of surgical intervention) are unclear. Whereas visuospatial memory is likely to either remain stable or improve after surgery, verbal memory is prone to post-surgical decline. In terms of the intervention type, SAH seems more beneficial than ATLR for visuospatial memory. On the other hand, mixed findings are reported regarding the effects of the type of surgical intervention on verbal memory. A meta-analysis of complications following ATLR reported psychiatric complications, visual field defects and cognitive disorders as most common (60). The fact that the efficacy and complications of open surgical techniques are so well-researched mean that it will require clear outcomes from minimally invasive techniques to replace surgical methods such as ATLR that have an established evidence base, including the results from this metaanalysis which provides further evidence for their efficacy in seizure control.

\section{Stereotactic Radiosurgery}

The estimate of the seizure-free rate per person-year for those undergoing radiosurgery was lower than that for open surgical methods such as ATLR and transcortical SAH. Additionally, there were only seven papers (three prospective) included in the meta-analysis for radiosurgery as compared with the 21 papers that looked at ATLR. The highest level of evidence arises from the ROSE randomized control trial which revealed inferiority of SRS compared to ATLR, despite this trial terminating early (11). The benefits of SRS include that it is an outpatient procedure and may be suitable for those patients unable or unwilling to undergo open surgery. Notable drawbacks are a delay in seizure cessation, post-treatment oedema with subsequent need for steroids, and the unexpected late effects of radiation must be considered.

No papers reported significant declines in verbal or visuospatial memory, intelligence or language. Notably, a published meta-analysis of neuropsychological outcomes criticized the methodological quality of SRS studies, calling for better prospective designed trials (61). A meta-analysis considering SRS published in 2016 reported an average of 14 months to seizure cessation. However, this analysis included studies with small sample sizes ( $<10$ patients) as well as other etiologies, including cavernous malformations (62).

\section{Radiofrequency}

This technique had the lowest seizure-free rate in our mixed effects linear regression model. The quality of evidence for this technique was low, with only one prospective study included in our analysis. Nevertheless, advantages associated with this technique are that it can be performed immediately following SEEG, it has a low risk safety profile and unlike gamma knife there is no latency of effect onset (63). Additionally, according to the same study, there was no need for corticosteroid use following RF-TC compared to SRS. RF-TC is unlikely to be successful as a stand-alone treatment for mesial temporal lobe epilepsy but transient reductions in seizure frequency may predict seizure free outcomes following subsequent open surgery. Such studies were not included in the quantitative analysis within the RFTC arm as the definitive intervention in these studies was open surgery.

\section{Laser Interstitial Thermal Therapy}

The first reported case of LITT was in 2010. In subsequent years, this technique has shown promising seizure effectiveness. Our mixed-effects model demonstrated overlapping 95\% confidence intervals with open surgical models. Visual field defects were the most reported complication in line with previous reports (64). Some of these included visual defects that were asymptomatic to the patient, some of which are not identified until formal visual field testing is done. Such asymptomatic patients might fail UK driving criteria once formal perimetry is conducted. The type of perimetry performed can also skew results, with Esterman perimetry (the current DVLA gold standard) being more lenient. We emphasize that it is crucial to conduct formal visual testing after epilepsy surgery, so that visual complications are not underestimated, and patients can be warned about the potential restrictions on driving. Laser ablation did not show a delayed treatment effect like radiosurgery and its evidence base was more reliable than that of radiofrequency, featuring several more studies. This presents this technique as a strong contender to open surgical methods. Dominantsided verbal memory decline seemed to be the most common neuropsychological complication but not all studies reported a decline, with an improvement in naming function reported. The much shorter hospital stay associated with LITT compared with ATLR also makes it an attractive first line alternative to open surgery (54). LITT may appear beneficial for post-operative neuropsychological outcome when directly compared with open surgery, perhaps due to relative sparing of the parahippocampal gyrus (50). Our comparative analysis suggested ATLR had the largest effect size estimate of all surgical techniques but overlap of the $95 \%$ confidence intervals with SAH and LITT prevents firm conclusions regarding superiority. It is possible, however, that LITT effectiveness is overestimated due to a positive reporting bias associated with novel technologies (halo effect), a reluctance to publish poor outcomes, shorter follow up durations and overcoming of learning curves. A systematic review comparing only the minimally invasive techniques LITT, RF-TC and SRS concluded that LITT shows promising seizure efficacy in the short-term (65). Our linear-regression model results provide a much-needed statistical analysis of the data in comparison to open surgical methods to further support LITT as an emerging technique, but long-term follow ups and direct comparisons are needed to form a firm conclusion. Additionally, we excluded overlapping data from our meta-analysis in order to avoid duplicate cohorts in our statistical analysis. 


\section{LIMITATIONS}

A notable limitation to the analysis is the varying duration of follow-ups and the significant heterogeneity between studies precluding accurate comparisons. Seizure remissions are known to fall with time and at long term follow-up only around 50\% of patients remain free of seizures following open surgery (66). With minimally invasive techniques, comparative follow up rates are shorter, and the durability of such techniques are less well characterized, particularly with SRS where the onset of effect is delayed. Most studies either reported seizure outcome at last follow-up or at pre-determined time intervals. This inconsistency in reporting follow-up times may mask those individuals that are seizure free at their last visit but go on to then subsequently have a seizure.

To mitigate this, we calculated the seizure free rate perperson year. As we do not know the time at which a patient relapses the entire follow up duration is taken as the time at risk. A limitation of this approach is that studies with longer follow up durations have a large number of patient years at risk, which may inflate effect size estimates for novel minimally invasive approaches. Similarly, techniques that result in late seizure recurrences provide the same results as early recurrences, which does not accurately reflect the real-world reduction in seizure burden. Future studies should, therefore, aim to provide more precise data regarding timing of seizure recurrence following surgery.

Another limitation to our analysis is that very few papers were RCTs. Few comparative studies reported whether they were sufficiently powered to detect differences between interventions. Very few studies conducted a prospective calculation of the study size or used blinding to carry out an unbiased assessment of the endpoint. This means that with the small sample sizes present in most publications, studies may have been underpowered to detect statistically significant differences in seizure freedom between interventions. A meta-analysis comparing seizure free outcomes between ATLR, SAH, RFTC and LITT was recently published which concluded that LITT was significantly less effective than open surgery (67). There are, however, significant methodological differences between our study. The main distinction is that they included studies with 6 months or greater follow up duration. It is widely accepted that open surgical techniques have greatest frequency of seizure recurrence within the first year of surgery (10), incorporating studies with 6 month follow up durations fail to capture this and favor short-term seizure free outcomes. Additionally, the Forest plots and heterogeneity statistics derived from the random effects model between anterior temporal lobectomy and LITT as well as selective amygdalohippocampectomy and LITT were statistically significant $(p<0.001)$. This level of heterogeneity may make such comparisons unreliable.

Only a quarter of the RF-TC papers had neuropsychological outcomes available, limiting our knowledge to one cohort. Additionally, the heterogeneity of neuropsychological tests amongst studies makes it more difficult to draw conclusions. The application of standardized neuropsychological tests administered to those undergoing resective, ablative, and radiosurgical techniques in the future would be of great benefit as it has also been suggested that studies are not using the most appropriate neuropsychological test for the cognitive domain they are testing (68).

Synthesizing complications following open surgery was difficult because of the heterogeneity of complications, no standardized scale for reporting and inconsistency in studies differentiating open surgical techniques (ATLR from SAH). Overall, we found a lower rate of VFDs for open surgery than in the contemporary literature highlighting the lack of formal perimetry testing and a lack of consistency in defining a "clinically significant defect." Within one review, only one study reported a visual field defect rate of $15 \%$, whilst the rates in the contemporary literature are significantly in excess of this (69).

\section{CONCLUSION}

Based on effect size estimations of seizure-free rates per person year, there is no evidence to suggest LITT is less effective than open surgical techniques in the short term but long-term outcome data is still lacking. Nevertheless, LITT is becoming a first-line treatment alternative in certain countries as it is more acceptable to patients and if unsuccessful, does not preclude subsequent ablations or open surgery. As with all new technologies, cost and learning curves remain a barrier. Open surgical techniques conveyed similar seizure-free outcomes but may be associated with varying neuropsychological and visual field deficit rates. A randomized control trial is now needed to compare LITT to open surgical methods.

Both SRS and RF-TC were the least effective methods at inducing seizure remission in our synthesis. SRS remains an option for patients that are unfit or do not wish to undergo open surgery. The evidence base for this technique is still limited, the onset of treatment effect is significantly delayed, and adverse effects, notably cerebral oedema, can be associated with severe morbidity.

Secondary outcome measures, such as neuropsychological outcome and intervention-related morbidity, are poorly reported but are important considerations when deciding on firstline intervention. Future studies should also evaluate benefits in secondary outcomes and would undoubtedly benefit from standardization of neuropsychological testing.

\section{DATA AVAILABILITY STATEMENT}

The original contributions presented in the study are included in the article/Supplementary Material, further inquiries can be directed to the corresponding authors.

\section{AUTHOR CONTRIBUTIONS}

$\mathrm{KM}, \mathrm{KD}, \mathrm{SB}, \mathrm{VV}, \mathrm{FX}$, and AA-M contributed to data acquisition and analysis. VV, KM, and JD were involved in the study conception, data interpretation, and drafting the manuscript. 
AO'K provided statistical expertise. All authors carried out critical review of the manuscript.

\section{FUNDING}

This research was funded in whole, or in part, by the Wellcome Trust [Grant Number WT - 106882/Z/15/Z]. For the purpose of Open Access, the author has applied a CC BY public copyright

\section{REFERENCES}

1. Vakharia VN, Duncan JS, Witt JA, Elger CE, Staba R, Engel J Jr. Getting the best outcomes from epilepsy surgery. Ann Neurol. (2018) 83:676-90. doi: 10.1002/ana.25205

2. Wiebe S, Blume WT, Girvin JP, Eliasziw M. Effectiveness, efficiency of surgery for temporal lobe epilepsy study G. A randomized, controlled trial of surgery for temporal-lobe epilepsy. $N$ Engl J Med. (2001) 345:311-8. doi: 10.1056/NEJM200108023450501

3. Engel J Jr, Wiebe S, French J, Sperling M, Williamson P, Spencer D, et al. Practice parameter: temporal lobe and localized neocortical resections for epilepsy: report of the quality standards subcommittee of the American Academy of Neurology, in association with the American Epilepsy Society and the American Association of Neurological Surgeons. Neurology. (2003) 60:538-47. doi: 10.1212/01.WNL.0000055086.35806.2D

4. Hermann B, Davies K, Foley K, Bell B. Visual confrontation naming outcome after standard left anterior temporal lobectomy with sparing versus resection of the superior temporal gyrus: a randomized prospective clinical trial. Epilepsia. (1999) 40:1070-6. doi: 10.1111/j.1528-1157.1999.tb0 0821.x

5. Niemeyer P. The Transventricular Amygdalohippocampectomy in Temporal Lobe Epilepsy. Temporal Lobe Epilepsy (1958).

6. Wieser HG, Yaşargil MG. Selective amygdalohippocampectomy as a surgical treatment of mesiobasal limbic epilepsy. Surg Neurol. (1982) 17:445-57. doi: 10.1016/S0090-3019(82)80016-5

7. Park TS, Bourgeois BF, Silbergeld DL, Dodson WE. Subtemporal transparahippocampal amygdalohippocampectomy for surgical treatment of mesial temporal lobe epilepsy. Technical note J Neurosurg. (1996) 85:1172-6. doi: 10.3171/jns.1996.85.6.1172

8. Kucukyuruk B, Richardson RM, Wen HT, Fernandez-Miranda JC, Rhoton AL Jr. Microsurgical anatomy of the temporal lobe and its implications on temporal lobe epilepsy surgery. Epilepsy Res Treat. (2012) 2012:769825. doi: 10.1155/2012/769825

9. Josephson CB, Dykeman J, Fiest KM, Liu X, Sadler RM, Jette N, et al. Systematic review and meta-analysis of standard vs selective temporal lobe epilepsy surgery. Neurology. (2013) 80:1669-76. doi: 10.1212/WNL.0b013e3182904f82

10. de Tisi J, Bell GS, Peacock JL, McEvoy AW, Harkness WF, Sander JW, et al. The long-term outcome of adult epilepsy surgery, patterns of seizure remission, and relapse: a cohort study. Lancet. (2011) 378:1388-95. doi: 10.1016/S0140-6736(11)60890-8

11. Barbaro NM, Quigg M, Ward MM, Chang EF, Broshek DK, Langfitt JT, et al. Radiosurgery versus open surgery for mesial temporal lobe epilepsy: The randomized, controlled ROSE trial. Epilepsia. (2018) 59:1198-207. doi: $10.1111 /$ epi.14045

12. Parrent AG, Blume WT. Stereotactic amygdalohippocampotomy for the treatment of medial temporal lobe epilepsy. Epilepsia. (1999) 40:1408-16. doi: 10.1111/j.1528-1157.1999.tb02013.x

13. Gross RE, Stern MA, Willie JT, Fasano RE, Saindane AM, Soares BP, et al. Stereotactic laser amygdalohippocampotomy for mesial temporal lobe epilepsy. Ann Neurol. (2018) 83:575-87. doi: 10.1002/ana.25180

14. Vakharia VN, Sparks R, Li K, O’Keeffe AG, Miserocchi A, McEvoy AW, et al. Automated trajectory planning for laser interstitial thermal therapy in mesial temporal lobe epilepsy. Epilepsia. (2018) 59:814-24. doi: 10.1111/epi.14034 license to any author accepted manuscript version arising from this submission.

\section{SUPPLEMENTARY MATERIAL}

The Supplementary Material for this article can be found online at: https://www.frontiersin.org/articles/10.3389/fneur. 2021.777845/full\#supplementary-material

15. Liberati A, Altman DG, Tetzlaff J, Mulrow C, Gøtzsche PC, Ioannidis JPA, et al. The PRISMA statement for reporting systematic reviews and metaanalyses of studies that evaluate healthcare interventions: explanation and elaboration. BMJ. (2009) 339:b2700. doi: 10.1136/bmj.b2700

16. West S, Nolan SJ, Cotton J, Gandhi S, Weston J, Sudan A, et al. Surgery for epilepsy. Cochrane Database Syst Rev. (2015) Cd010541. doi: 10.1002/14651858.CD010541.pub2

17. Tonini C, Beghi E, Berg AT, Bogliun G, Giordano L, Newton RW, et al. Predictors of epilepsy surgery outcome: a meta-analysis. Epilepsy Res. (2004) 62:75-87. doi: 10.1016/j.eplepsyres.2004.08.006

18. Kuang Y, Yang T, Gu J, Kong B, Cheng L. Comparison of therapeutic effects between selective amygdalohippocampectomy and anterior temporal lobectomy for the treatment of temporal lobe epilepsy: a meta-analysis. $\mathrm{Br} \mathrm{J}$ Neurosurg. (2014) 28:374-7. doi: 10.3109/02688697.2013.841854

19. Slim K, Nini E, Forestier D, Kwiatkowski F, Panis Y, Chipponi J. Methodological index for non-randomized studies (minors): development and validation of a new instrument. ANZ J Surg. (2003) 73:712-6. doi: 10.1046/j.1445-2197.2003.02748.x

20. Jadad AR, Moore RA, Carroll D, Jenkinson C, Reynolds DJ, Gavaghan DJ, et al. Assessing the quality of reports of randomized clinical trials: is blinding necessary? Control Clin Trials. (1996) 17:1-12. doi: 10.1016/0197-2456(95)00134-4

21. Wendling AS, Hirsch E, Wisniewski I, Davanture C, Ofer I, Zentner J, et al. Selective amygdalohippocampectomy versus standard temporal lobectomy in patients with mesial temporal lobe epilepsy and unilateral hippocampal sclerosis. Epilepsy Res. (2013) 104:94-104. doi: 10.1016/j.eplepsyres.2012.09.007

22. Alonso-Vanegas MA, Freire Carlier ID, San-Juan D, Martínez AR, Trenado C. Parahippocampectomy as a new surgical approach to mesial temporal lobe epilepsy caused by hippocampal sclerosis: a pilot randomized comparative clinical trial. World Neurosurg. (2018) 110:e1063-e71. doi: 10.1016/j.wneu.2017.11.170

23. Schramm J, Lehmann TN, Zentner J, Mueller CA, Scorzin J, Fimmers R. et al. Randomized controlled trial of $25-\mathrm{cm}$ versus $35-\mathrm{cm}$ mesial temporal resection-Part 2: volumetric resection extent and subgroup analyses. Acta Neurochir. (2011) 153:221-8. doi: 10.1007/s00701-010-0901-5

24. Lee T, Mackenzie RA, Walker AJ, Matheson JM, Sachdev P. Effects of left temporal lobectomy and amygdalohippocampectomy on memory. J Clin Neurosci. (1997) 4:314-9. doi: 10.1016/S0967-5868(97)90098-9

25. Mackenzie RA, Matheson J, Ellis M, Klamus J. Selective versus nonselective temporal lobe surgery for epilepsy. J Clin Neurosci. (1997) 4:152-4. doi: 10.1016/S0967-5868(97)90064-3

26. Arruda F, Cendes F, Andermann F, Dubeau F, Villemure JG, Jones-Gotman $\mathrm{M}$, et al. Mesial atrophy and outcome after amygdalohippocampectomy or temporal lobe removal. Ann Neurol. (1996) 40:446-50. doi: 10.1002/ana.410400314

27. Elliott CA, Broad A, Narvacan K, Steve TA, Snyder T, Urlacher J, et al. Seizure outcome in pediatric medically refractory temporal lobe epilepsy surgery: selective amygdalohippocampectomy versus anterior temporal lobectomy. $J$ Neurosurg Pediatr. (2018) 22:276-82. doi: 10.3171/2018.4.PEDS17607

28. Moles A, Guenot M, Rheims S, Berthiller J, Catenoix H, Montavont A, et al. SEEG-guided radiofrequency coagulation (SEEG-guided RF-TC) versus anterior temporal lobectomy (ATL) in temporal lobe epilepsy. J Neurol. (2018) 265:1998-2004. doi: 10.1007/s00415-018-8958-9 
29. Foged MT, Vinter K, Stauning L, Kjaer TW, Ozenne B, Beniczky S, et al. Verbal learning and memory outcome in selective amygdalohippocampectomy versus temporal lobe resection in patients with hippocampal sclerosis. Epilepsy Behav. (2018) 79:180-7. doi: 10.1016/j.yebeh.2017.12.007

30. Sagher O, Thawani JP, Etame AB, Gomez-Hassan DM. Seizure outcomes and mesial resection volumes following selective amygdalohippocampectomy and temporal lobectomy. Neurosurg Focus. (2012) 32:E8. doi: 10.3171/2011.12.FOCUS11342

31. Bujarski KA, Hirashima F, Roberts DW, Jobst BC, Gilbert KL, Roth RM, et al. Long-term seizure, cognitive, and psychiatric outcome following transmiddle temporal gyrus amygdalohippocampectomy and standard temporal lobectomy. J Neurosurg. (2013) 119:16-23. doi: 10.3171/2013.3.JNS12714

32. Morino $M$, Uda $T$, Naito $K$, Yoshimura $M$, Ishibashi $K$, Goto $T$, et al. Comparison of neuropsychological outcomes after selective amygdalohippocampectomy versus anterior temporal lobectomy. Epilepsy Behav. (2006) 9:95-100. doi: 10.1016/j.yebeh.2006.04.017

33. Tanriverdi T, Dudley RW, Hasan A, Al Jishi A, Al Hinai Q, Poulin N, et al. Memory outcome after temporal lobe epilepsy surgery: corticoamygdalohippocampectomy versus selective amygdalohippocampectomy. J Neurosurg. (2010) 113:1164-75. doi: 10.3171/2009.10.JNS09677

34. Clusmann H, Schramm J, Kral T, Helmstaedter C, Ostertun B, Fimmers $\mathrm{R}$, et al. Prognostic factors and outcome after different types of resection for temporal lobe epilepsy. J Neurosurg. (2002) 97:1131-41. doi: 10.3171/jns.2002.97.5.1131

35. Mansouri A, Fallah A, McAndrews MP, Cohn M, Mayor D, Andrade D, et al. Neurocognitive and seizure outcomes of selective amygdalohippocampectomy versus anterior temporal lobectomy for mesial temporal lobe epilepsy. Epilepsy Res Treat. (2014) 2014:306382. doi: $10.1155 / 2014 / 306382$

36. Nascimento FA, Gatto LA, Silvado C, Mäder-Joaquim MJ, Moro MS, Araujo JC. Anterior temporal lobectomy versus selective amygdalohippocampectomy in patients with mesial temporal lobe epilepsy. Arq Neuropsiquiatr. (2016) 74:35-43. doi: 10.1590/0004-282X20150188

37. Quigg M, Barbaro NM, Ward MM, Chang EF, Broshek DK, Langfitt JT, et al. Visual field defects after radiosurgery versus temporal lobectomy for mesial temporal lobe epilepsy: findings of the ROSE trial. Seizure. (2018) 63:62-7. doi: 10.1016/j.seizure.2018.10.017

38. Mohan M, Keller S, Nicolson A, Biswas S, Smith D, Osman Farah J, et al. The long-term outcomes of epilepsy surgery. PloS ONE. (2018) 13:e0196274. doi: 10.1371/journal.pone.0196274

39. Fan X, Shan Y, Lu C, An Y, Wang Y, Du J, et al. Optimized SEEGguided radiofrequency thermocoagulation for mesial temporal lobe epilepsy with hippocampal sclerosis. Seizure. (2019) 71:304-11. doi: 10.1016/j.seizure.2019.08.011

40. Vojtěch Z, Malíková H, Krámská L, AnýŽ J, Syruček M, Zámečník J, et al. Long-term seizure outcome after stereotactic amygdalohippocampectomy. Acta Neurochir. (2014) 156:1529-37. doi: 10.1007/s00701-014-2126-5

41. Malikova H, Kramska L, Vojtech Z, Liscak R, Sroubek J, Lukavsky J, et al. Different surgical approaches for mesial temporal epilepsy: resection extent, seizure, and neuropsychological outcomes. Stereotact Funct Neurosurg. (2014) 92:372-80. doi: 10.1159/000366003

42. Rheims S, Fischer C, Ryvlin P, Isnard J, Guenot M, Tamura M, et al. Longterm outcome of gamma-knife surgery in temporal lobe epilepsy. Epilepsy Res. (2008) 80:23-9. doi: 10.1016/j.eplepsyres.2008.03.003

43. Vojtech Z, Vladyka V, Kalina M, Nespor E, Seltenreichová K, Semnická J, et al. The use of radiosurgery for the treatment of mesial temporal lobe epilepsy and long-term results. Epilepsia. (2009) 50:2061-71. doi: 10.1111/j.1528-1167.2009.02071.x

44. Régis J, Rey M, Bartolomei F, Vladyka V, Liscak R, Schröttner O, et al. Gamma knife surgery in mesial temporal lobe epilepsy: a prospective multicenter study. Epilepsia. (2004) 45:504-15. doi: 10.1111/j.0013-9580.2004.07903.x

45. Barbaro NM, Quigg M, Broshek DK, Ward MM, Lamborn KR, Laxer KD, et al. A multicenter, prospective pilot study of gamma knife radiosurgery for mesial temporal lobe epilepsy: seizure response, adverse events, and verbal memory. Ann Neurol. (2009) 65:167-75. doi: 10.1002/ana.21558

46. Quigg M, Broshek DK, Barbaro NM, Ward MM, Laxer KD, Yan G, et al. Neuropsychological outcomes after gamma knife radiosurgery for mesial temporal lobe epilepsy: a prospective multicenter study. Epilepsia. (2011) 52:909-16. doi: 10.1111/j.1528-1167.2011.02987.x

47. Bartolomei F, Hayashi M, Tamura M, Rey M, Fischer C, Chauvel P, et al. Longterm efficacy of gamma knife radiosurgery in mesial temporal lobe epilepsy. Neurology. (2008) 70:1658-63. doi: 10.1212/01.wnl.0000294326.05118.d8

48. Vojtěch Z, Malíková H, Syruček M, Krámská L, Šroubek J, Vladyka V, et al. Morphological changes after radiosurgery for mesial temporal lobe epilepsy. Acta Neurochir. (2015) 157:1783-92. doi: 10.1007/s00701-015-2525-2

49. Willie JT, Laxpati NG, Drane DL, Gowda A, Appin C, Hao C, et al. Real-time magnetic resonance-guided stereotactic laser amygdalohippocampotomy for mesial temporal lobe epilepsy. Neurosurgery. (2014) 74:569-85. doi: 10.1227/NEU.0000000000000343

50. Drane DL, Loring DW, Voets NL, Price M, Ojemann JG, Willie JT, et al. Better object recognition and naming outcome with MRI-guided stereotactic laser amygdalohippocampotomy for temporal lobe epilepsy. Epilepsia. (2015) 56:101-13. doi: $10.1111 /$ epi.12860

51. Tao JX, Wu S, Lacy M, Rose S, Issa NP, Yang CW, et al. Stereotactic EEGguided laser interstitial thermal therapy for mesial temporal lobe epilepsy. $J$ Neurol Neurosurg Psychiatry. (2018) 89:542. doi: 10.1136/jnnp-2017-316833

52. Le S, Ho AL, Fisher RS, Miller KJ, Henderson JM, Grant GA, et al. Laser interstitial thermal therapy (LITT): seizure outcomes for refractory mesial temporal lobe epilepsy. Epilepsy Behav. (2018) 89:37-41. doi: 10.1016/j.yebeh.2018.09.040

53. Jermakowicz WJ, Kanner AM, Sur S, Bermudez C, D’Haese PF, Kolcun JPG, et al. Laser thermal ablation for mesiotemporal epilepsy: Analysis of ablation volumes and trajectories. Epilepsia. (2017) 58:801-10. doi: 10.1111/epi.13715

54. Kang JY, Wu C, Tracy J, Lorenzo M, Evans J, Nei M, et al. Laser interstitial thermal therapy for medically intractable mesial temporal lobe epilepsy. Epilepsia. (2015) 57:325-34. doi: 10.1111/epi.13284

55. Youngerman BE, Oh JY, Anbarasan D, Billakota S, Casadei CH, Corrigan $\mathrm{EK}$, et al. Laser ablation is effective for temporal lobe epilepsy with and without mesial temporal sclerosis if hippocampal seizure onsets are localized by stereoelectroencephalography. Epilepsia. (2018) 59:595-606. doi: 10.1111/epi.14004

56. Wu C, Jermakowicz WJ, Chakravorti S, Cajigas I, Sharan AD, Jagid JR, et al. Effects of surgical targeting in laser interstitial thermal therapy for mesial temporal lobe epilepsy: a multicenter study of 234 patients. Epilepsia. (2019) 60:1171-83. doi: 10.1111/epi.15565

57. Cajigas I, Kanner AM, Ribot R, Casabella AM, Mahavadi A, Jermakowicz $\mathrm{W}$, et al. Magnetic resonance-guided laser interstitial thermal therapy for mesial temporal epilepsy: a case series analysis of outcomes and complications at 2-year follow-up. World Neurosurg. (2019) 126:e1121-e9. doi: 10.1016/j.wneu.2019.03.057

58. Donos C, Breier J, Friedman E, Rollo P, Johnson J, Moss L, et al. Laser ablation for mesial temporal lobe epilepsy: surgical and cognitive outcomes with and without mesial temporal sclerosis. Epilepsia. (2018) 59:1421-32. doi: $10.1111 /$ epi. 14443

59. Grewal SS, Alvi MA, Lu VM, Wahood W, Worrell GA, Tatum W, et al. Magnetic resonance-guided laser interstitial thermal therapy versus stereotactic radiosurgery for medically intractable temporal lobe epilepsy: a systematic review and meta-analysis of seizure outcomes and complications. World Neurosurg. (2019) 122:e32-47. doi: 10.1016/j.wneu.2018.08.227

60. Brotis AG, Giannis T, Kapsalaki E, Dardiotis E, Fountas KN. Complications after anterior temporal lobectomy for medically intractable epilepsy: a systematic review and meta-analysis. Stereotact Funct Neurosurg. (2019) 97:69-82. doi: 10.1159/000500136

61. Witt JA, Hoppe C, Helmstaedter C. Neuropsychologist's (re-)view: resective versus ablative amygdalohippocampectomies. Epilepsy Res. (2018) 142:161-6. doi: 10.1016/j.eplepsyres.2017.08.017

62. Feng ES, Sui CB, Wang TX, Sun GL. Stereotactic radiosurgery for the treatment of mesial temporal lobe epilepsy. Acta Neurol Scand. (2016) 134:442-51. doi: 10.1111/ane.12562

63. Kalina M, Lisck R, Vojtech Z, Adamkova E, Prochazka T, Mareckova I, et al. Stereotactic amygdalohippocampectomy for temporal lobe epilepsy: promising results in 16 patients. Epileptic Disord. (2007) 9 Suppl 1:S68-74. doi: 10.1684/epd.2008.0158

64. Waseem H, Vivas AC, Vale FL. MRI-guided laser interstitial thermal therapy for treatment of medically refractory non-lesional mesial temporal lobe 
epilepsy: outcomes, complications, and current limitations: a review. J Clin Neurosci. (2017) 38:1-7. doi: 10.1016/j.jocn.2016.12.002

65. Wang R, Beg U, Padmanaban V, Abel TJ, Lipsman N, Ibrahim GM, et al. A systematic review of minimally invasive procedures for mesial temporal lobe epilepsy: too minimal, too fast? Neurosurgery. (2021) 89:164-76. doi: 10.1093/neuros/nyab125

66. Aull-Watschinger S, Pataraia E, Czech T, Baumgartner C. Outcome predictors for surgical treatment of temporal lobe epilepsy with hippocampal sclerosis. Epilepsia. (2008) 49:1308-16. doi: 10.1111/j.1528-1167.2008.01732.x

67. Kohlhase K, Zollner JP, Tandon N, Strzelczyk A, Rosenow F. Comparison of minimally invasive and traditional surgical approaches for refractory mesial temporal lobe epilepsy: a systematic review and meta-analysis of outcomes. Epilepsia. (2021) 62:831-45. doi: 10.1111/epi.16846

68. Witt J-A, Meschede C, Helmstaedter C. Hazardous employment of invalid measures for cognitive outcome assessment: you only see what your test can show you. Epilepsy \& Behavior. (2021) 117:107865. doi: 10.1016/j.yebeh.2021.107865

69. Vakharia VN, Diehl B, Tisdall M. Visual field defects in temporal lobe epilepsy surgery. Curr Opin Neurol. (2021) 34:188-96. doi: 10.1097/WCO.000000000000090
Conflict of Interest: The authors declare that the research was conducted in the absence of any commercial or financial relationships that could be construed as a potential conflict of interest.

The handling editor declared a past co-authorship with one of the authors JD.

Publisher's Note: All claims expressed in this article are solely those of the authors and do not necessarily represent those of their affiliated organizations, or those of the publisher, the editors and the reviewers. Any product that may be evaluated in this article, or claim that may be made by its manufacturer, is not guaranteed or endorsed by the publisher.

Copyright $\odot 2021$ Marathe, Alim-Marvasti, Dahele, Xiao, Buck, O'Keeffe, Duncan and Vakharia. This is an open-access article distributed under the terms of the Creative Commons Attribution License (CC BY). The use, distribution or reproduction in other forums is permitted, provided the original author(s) and the copyright owner(s) are credited and that the original publication in this journal is cited, in accordance with accepted academic practice. No use, distribution or reproduction is permitted which does not comply with these terms. 